\title{
Prevention and Control Measures for Vertical Spread of Fire along the External Wall of High-rise Buildings
}

Jinliang Shao ${ }^{1}$, Leilei Shao ${ }^{2}$

${ }^{1}$ Sanmenxia Institute of City Planning and Exploring Urban Architecture, Henan, 472000,

${ }^{2}$ Shanghai Youan Architectural Design Co., Ltd, Shanghai 200439

\begin{abstract}
In the analysis and research of few cases on the characteristics of vertical "burning" and spreading of fire in high-rise buildings in China and overseas, the mechanism of vertical spreading of fire along external wall is caused by hot pressing and wind pressure existing in high-rise buildings. The use of external wall combustible materials and near-window combustible items resulted in the formation of high temperature pyrotechnics and the burning of the external wall. Besides, due to the lack of fire-fighting measurements in high-rise building, it is recommended that the external wall of the high-rise building should be equipped with vertical fire-proof partitioning and non-combustible materials by setting up an automatic fire-fighting water curtain system along the vertical section of the external wall and above the indoor window. Therefore, the automatic sprinkler can be set up to prevent the fire from spreading vertically along the external wall of the building effectively.
\end{abstract}

Keywords: High-rise Building; Vertical Fire Spread; External Wall Automatic Fire Extinguishing Water Curtain System; Automatic Window Nozzle

Publication date: March, 2019

Publication online: 31 March, 2019

Corresponding Author: Jinliang Shao, smxsj12003@ sina.com

\section{Introduction}

Since the ancient time, fires have been one of the biggest threat to building safety and causes of major lost to life and property. Due to the lack of fire facilities and capabilities to extinguish fire in high-rise buildings, high-rise buildings face the biggest problem in fire prevention and control which has been an issue taken by the government seriously. However, there are numerous events of fire outbreak occurring every year, which proves the danger of fire in high-rise building and the difficulties in rescuing people from it. In November 15, 2010, a fire broke out in one of the highrise teacher's apartment on the 28th floor of Jiaozhou Road, Jing'an District, Shanghai. Even with the highest efforts for firefighters to rescue, the fire outbreak took four and a half hours before being extinguished. As a result, 58 people were killed, and major properties lost were caused $^{[1]}$ as seen in Figure 1.

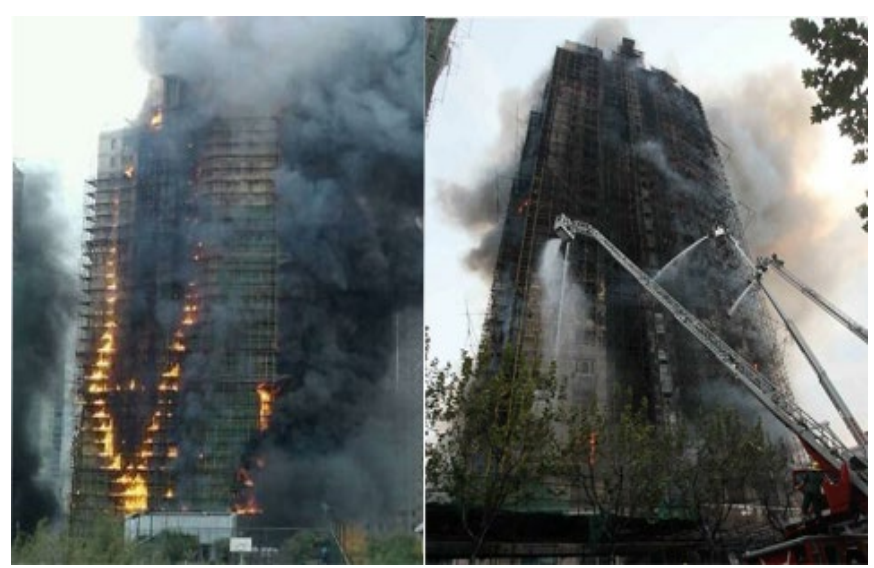

Figure 1. High-rise teacher's apartment fire outbreak on the 28th floor of Jiaozhou Road, Jing'an District, Shanghai in November 15, 2010

Shortly after the tragedy has happened, the national fire front summed up the fire lessons of the teacher's apartment in Shanghai. Besides that, on New Year's Eve of February 3, 2011, the first high-rise building in the northeast of Shenyang, which was 150 meters high and the first high-rise building in the northeast of Shenyang, had a fire outbreak. A fire broke out in Block A and 
Block B of the International Building as shown in Figure 2. After a many firefighting forces in Shenyang and surrounding cities were mobilized, it was burned continuously for 9 hours before the fire was finally extinguished. Eventually, it took a total of 17 hours to fully clear of the outbreak.

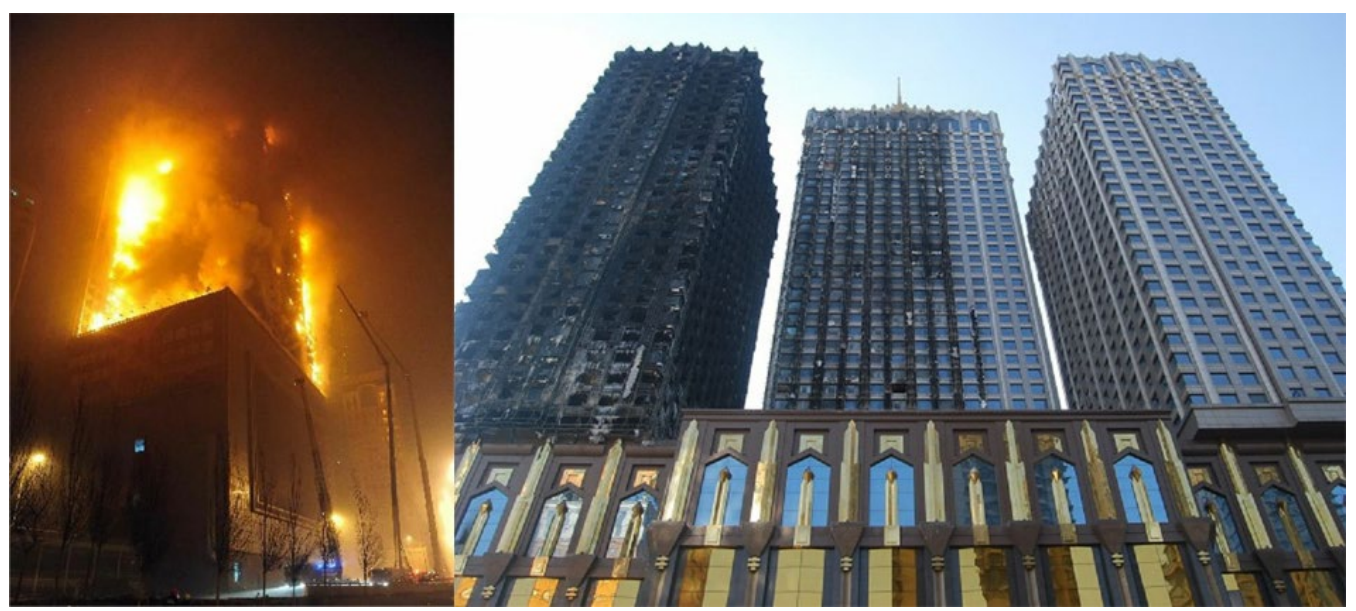

Figure 2. February 3, 2011, Fire outbreak in block A and block B of Huangchao Wanxin International Building, Youth Street, Heping District, Shenyang

On January 1, 2016's New Year's Eve, the Adris Hotel near Burj Khalifa in Dubai burst into flames. The flames went up to 300 meters high and there were a lot of debris falling from the sky. The smoke was rolling and there was an explosion. The fire has spread through the façade and windows as well as to the top of the building as seen in Figure 3.

After carefully analyzing the texts, pictures and video

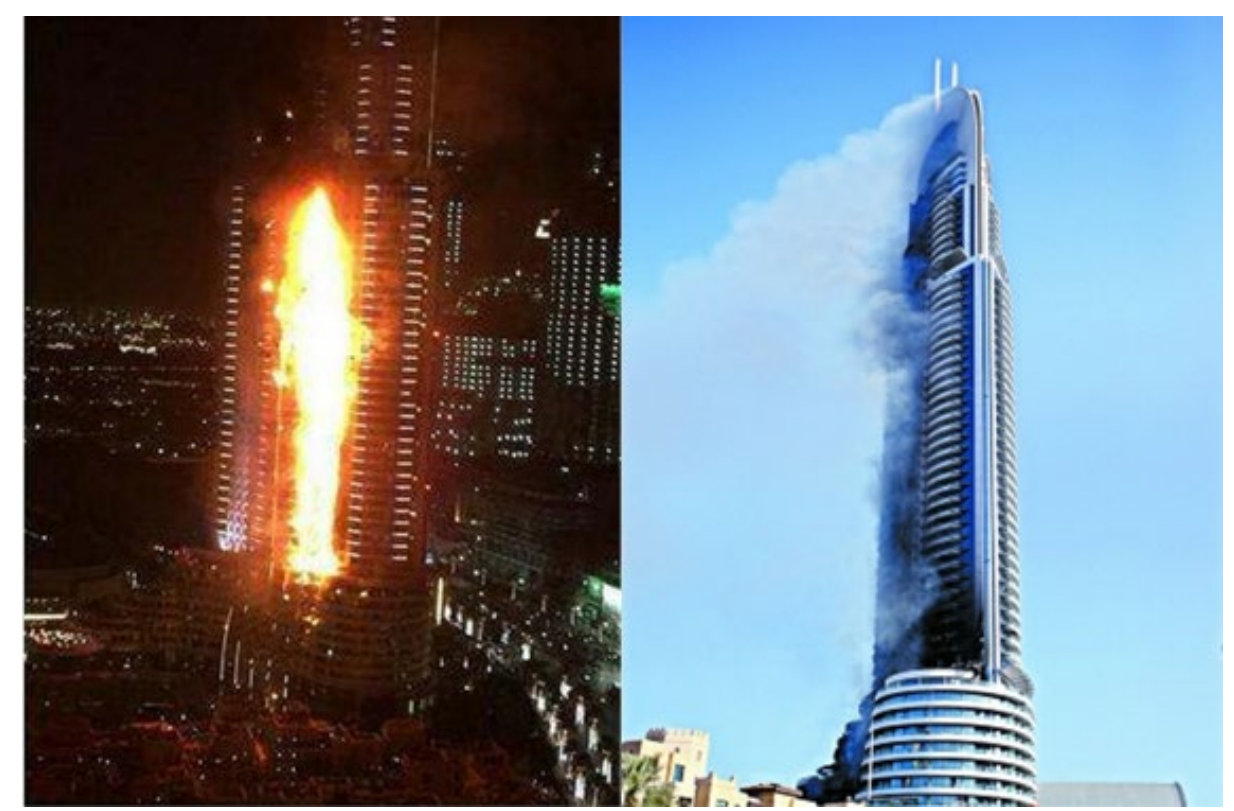

Figure 3. January 1, 2016, the Adris Hotel burst into flames

reports of these high-rise building fire scenes, it is inferred that fire outbreak of these high-rise buildings is spread upwards and downwards throughout the external wall windows, wall insulation materials and glass curtain walls. Which can be concluded as a typical case of vertical fire spread on the external walls of high-rise buildings.

\section{Cause of fire and its process of spreading}

According to media reports and published contents of some fire accidents, it is possible to clearly understand the cause and spread of the fire.

The fire in the Shanghai Jing'an high-level teacher's apartment was caused by the electric welding sparks 
igniting the nylon protective net on the outside of the scaffolding that was being built for energy-saving renovation of the external wall. The initial fire occurred on the tenth floor and eventually spread through the nylon fences, exterior insulation and near-window items to the lower layer then to the top until the roof.

Secondly, the fire in Shenyang Wanxin Building was caused by fireworks falling on the plastic lawn of the outdoor platform of Room 1109 on the 11th floor of Block B. After igniting the plastic lawn, the fire spread rapidly upwards through the rubber strip and foam of the aluminum-plastic composite panel to the external wall, rods and insulation extruded boards. Then, due to the high temperature baking, the exterior window glass of the building broke and the combustible objects in the room are ignited to form a large-area three-dimensional combustion. Moreover, due to firefighting trucks and rescue reaching the height limit of power supply and fire host, the fire was spread rapidly to the roof and eventually engulfed the entire tower. Plus, Block A, which was very near to Black B, was also affected by the burn due to the heat radiation.

Through detailed observation, these high-rise building fires spread rapidly upward through the external wall and near-window objects, presenting a vertical "string burning" feature as shown in Figure 4.

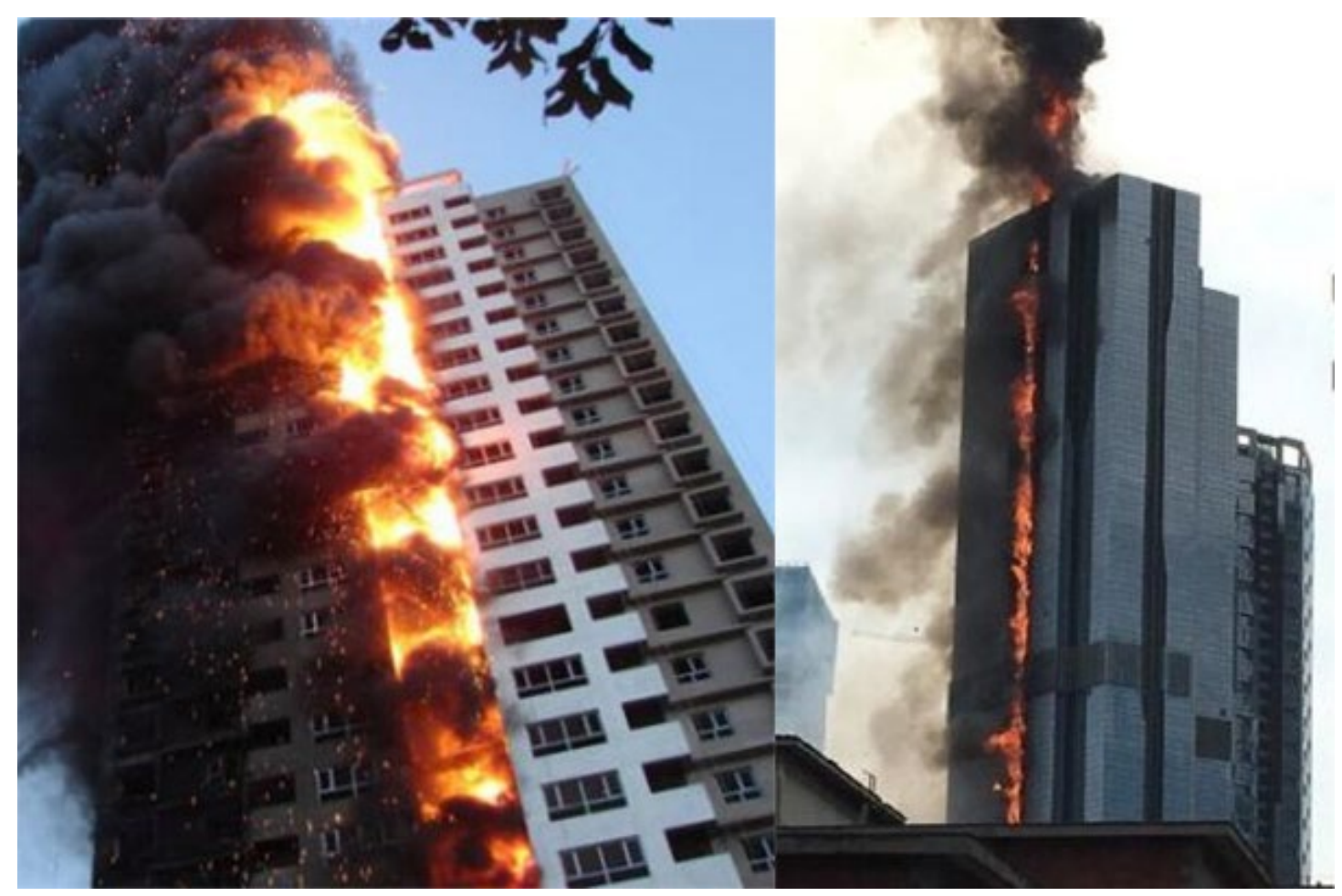

Figure 4. Spreading of fire through the external wall of High-rise building

\section{Mechanism of vertical spreading fire along the external walls of high-rise buildings}

The characteristics of vertical "string burning" in highrise building fires are mainly related to the airflow of the external wall. During an event of low wind for lowrise and multi-store buildings, the fire will start from the inner room window then radiate and burn vertically towards the outer window due to the obstruction between the surrounding buildings. However, high-rise building allows strong wind and fire that can spread into the room due to the lack of obstructions of surrounding buildings even in an event of low wind. The high temperature fire is spread radially from the room window and then up towards the external wall, forming a paste burning. Plus, another reason that caused the fire to spread in this way is the effect of hot pressing and wind pressure of the surrounding, which has a large chimney impact inside a high-rise building. Moreover, the airflow along the surface of a high-rise building is strongly affected by the height of the building; higher a building is, the faster the fire spreads. Then, the upper façade glass will quickly burst into flames as the high temperature continues to bake, eventually igniting curtains, bedding, mattresses and other combustible items and furniture in the room. When that occur, high temperate will cause the upper glass to be shatter, forming a vertical "string burning" spread state, 
and the external is then flared and burned towards up. The broken glass of the upper layer, the decorative material of the detached exterior wall and the burning fragments are not vertical when they are subjected to the impact and floating of the turbulent airflow caused by the fire but are radially diffused. Finally, it will break the outer window glass of the lower room, and the scattered flames and the residual fire will be spread into the lower room by the wind, which eventually spread towards the bottom as shown in figure 5 .

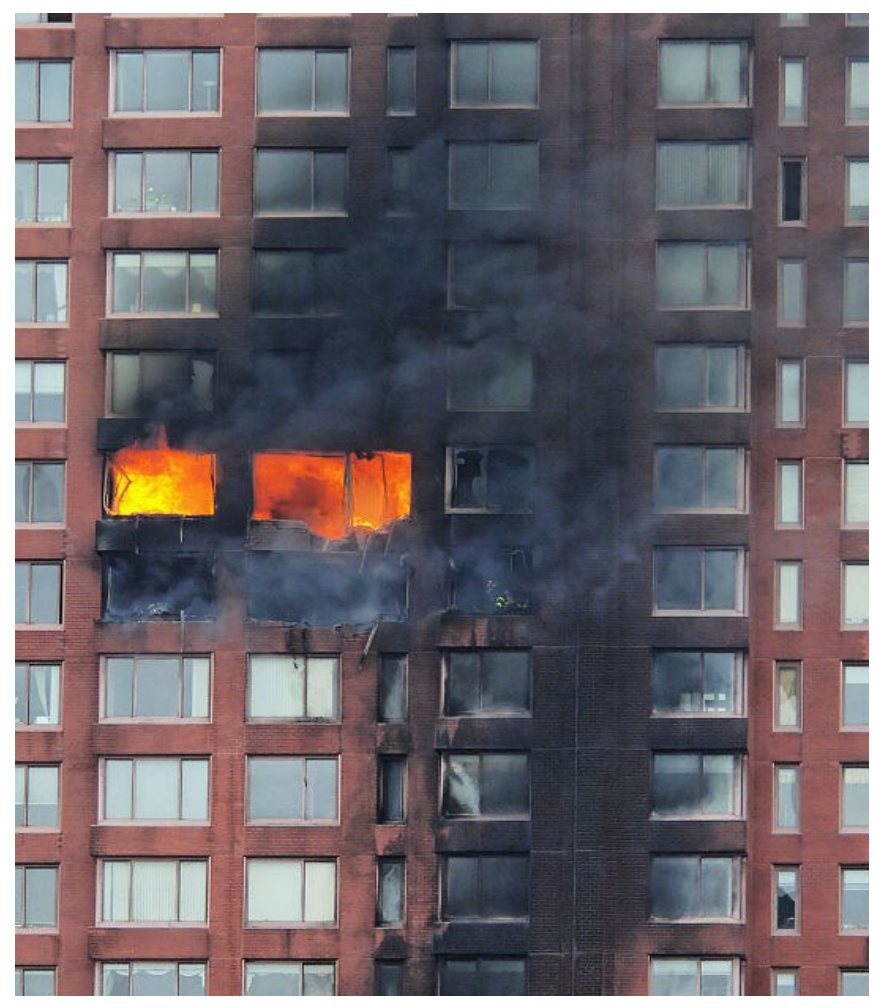

Figure 5. High-rise building on fire

\section{Current limitations of fire protection in high-rise building}

In this era, most countries have limited outdoor firefighting capacity such as low water pressure, insufficient water volume, lack of large-scale fire-fighting trucks and high-altitude fire-fighting facilities as well as limited height of fire-fighting water spray. In China's small and medium-sized cities, more than 24 meters and 50 meters for large cities' outdoor fire facilities have been unable. High-rise buildings, especially highzone fires, can only be depend on self-rescue, and their self-rescue measures are limited to indoor fire hydrant systems and automatic sprinkler systems. However, in order to play the role of firefighting and fire control on time, the indoor fire hydrant system has many restrictions. Generally, it can only save and control the horizontal spread of fire in the same layer of high-rise buildings, and the vertical spread of fire on the external wall of high-rise buildings are impossible to control. In particular, the vertical spread of fire on the external wall is more difficult to control and save with the help of municipal firefighting forces due to the lack of fire ascending surface as shown in figure 6 .

The setting of the automatic sprinkler system is limited to high-grade buildings. Therefore, except for apartments with a height of more than 50 meters, the nozzles are not arranged in the corridor and the firefighting capacity is limited for any other ordinary highrise residential buildings and apartments. Moreover, the location of the automatic sprinkler head is installed and the method of extinguishing the fire also have great limitations. As an example, the fire in Shenyang Wanxin Building started from the external platform, which then ignited the aluminum-plastic panel sealing rubber strip on the external wall and its insulation material as well as the indoor curtains and articles while the nozzle is generally located in the middle of the walkway and the room roof and the inner wall. When the highrise building is on fire, the window will form a lower opening to the room to allow wind to flow in with the fire and smoke. Then, the upper mouth will smoke from 
the indoors and the speed of the spreading to the inside of the room is very slow, therefore the heat radiation is not high.

In conclusion, it is difficult for side wall nozzles installed on the inner wall surface to burst into sprinkles on time and it is impossible to prevent the fire from spreading rapidly through the outer wall as shown in figure $7^{[2]}$.

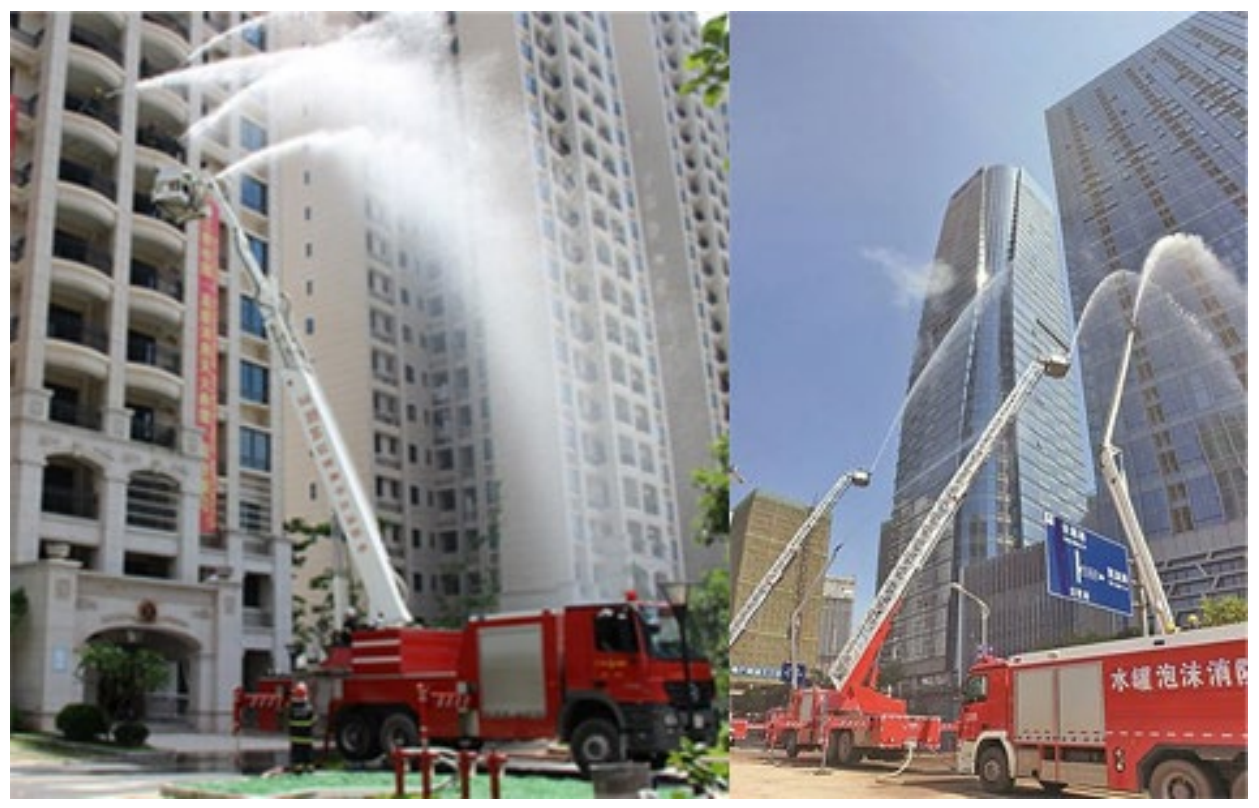

Figure 6. Municipal fire protection facilities

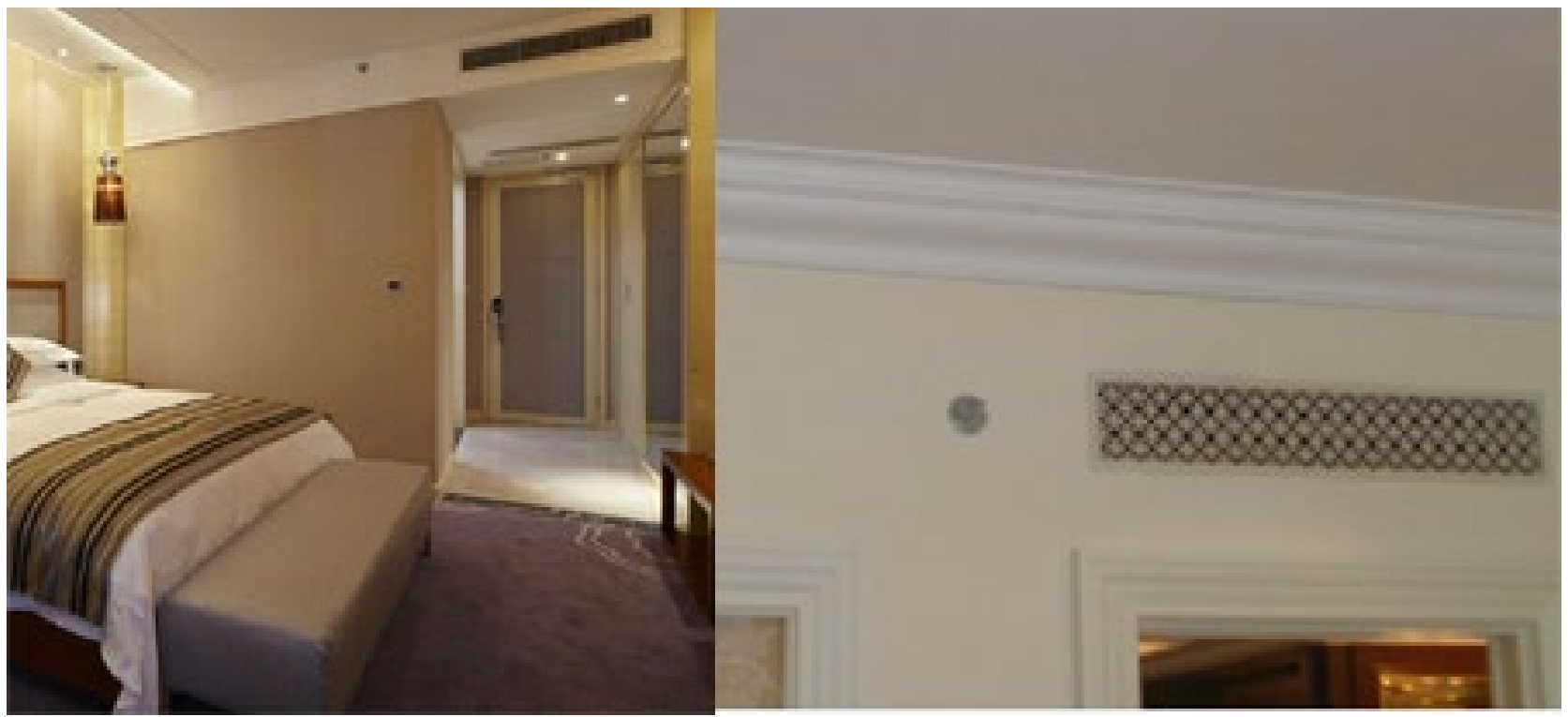

Figure 7. Pictures of side wall nozzle mounting commonly used in rooms and apartments

As the structure of multi-storey buildings are all built differently, each floor of the high-rise building has one or several independent fire compartments. The stairwells, elevators and pipelines between the floors are equipped with fireproof blocking measures. Fire doors are also installed. Therefore, there is little chance that fires in the high-rise buildings will spread vertically through the interior but generally spread along the windows of the outer walls. The measures to save the fire from the external walls are the blind spots for the design and construction of fire protection especially the high areas. Plus, due to the inability of municipal firefighting, fire control and firefighting are in a blank area, therefore firefighters have difficulty in extinguishing fires in the event of fire.

Secondly, with the airflow affecting the speed of the fire around the high-rise buildings, this vertical burning will occur very quickly. Usually, large number of high- 
temperature toxic fumes will quickly fill the upper room through the entrainment effect, causing the panicked residents to lose their escape direction and selfrescue ability and eventually leads to high casualties. Therefore, preventing the vertical spread of high-rise buildings along the outer wall is a major issue faced by the fire protection field of high-rise buildings. It does not only have a negative impact on the booming highrise construction industry, but also constitutes the safety of thousands of people's lives and property. As result, a major threat has been generated in high-rise building's fire safety and caused a phobia among workers in some residents and high-rise buildings.

\section{Prevention and control measures for vertical spread of fire on the external wall of high- rise buildings}

It is necessary to proceed from the three aspects of "defense", "control" and "elimination" to prevent highrise building fires from spreading vertically along the external wall windows and glass curtain walls effectively ${ }^{[3]}$.

Firstly, starting with "defense", design specifications of fire protection in national high-rise building according to the height of the building such as building with or without window sill wall, filling materials and gap sealing measures are mandatory. However, the fire breakout cases on the mentioned high-rise buildings can still pass through the building exterior wall windows. The rapid vertical spreading of fire is mainly caused by the entrainment of the fire on the outer wall of the high-rise building. The fire scene proves that when the entrainment effect of the window sill wall is not less than $800 \mathrm{~mm}$ high, it cannot be blocked. Therefore, the safety height of the window sill wall between the high-rise building layers needs a further study, which requires both building transparency and fire prevention. It is debatable whether it is safe to use fireproof glass for windows and glass curtain walls with insufficient height of window sills.

In order to build energy-saving countries around the world, the building exterior wall insulation measures are being enforced. However, currently in this era, the external wall insulation materials still cannot meet the requirements of the external wall surface that should be firm, fireproof and insulated. Throughout many lessons learnt from major fires event in high-rise buildings caused by poor fire resistance of building exterior wall insulation materials in recent years, it is necessary to introduce some regulations on strengthening fire prevention measures for exterior wall insulation materials. However, the building exterior wall insulation materials, which should be both solid, fireproof and heat-insulated, have yet to be developed and promoted quickly enough in this era. In addition, regardless of whether it is office, hotel, residential or apartment, the design of high-rise building's interior curtains and near-outdoor windows to test its flammability should be mandatory. Plus, residents should always call their property management department to conduct a regular fire prevention for their building. Last but not least, safety warning and preventive measures education should be implemented to share among residents to strengthen the prevention in case of fire outbreaks.

Second steps proceeding from "defense" is to "control". The easiest method to overcome the current situation of insufficient fire-fighting capacity in high-rise building is to install an automatic sprinkler water curtain system at a certain height along the external wall. The three main functions are to suppress the flames and hightemperature smoke from the window, to cool out the fire on the external wall and the lower glass to prevent the glass from being broken due to high temperature baking and finally is to extinguish the scattered residual fire and prevent the fire from spreading to the periphery. Thirdly, proceeding from "control" is to "eliminate. In the modern world today, majority of the automatic sprinkler systems are focused inside the building instead of externally. The position of the nozzle is usually arranged on the indoor side and the situation in which the fire propagates vertically through the external wall window is not considered. Therefore, it is a compulsory that the window nozzle can combine with the curtain box and the decorative lamp channel. Then, when the window is heated, and the temperature raises quickly, the fire from the window and the burning of the indoor curtain and the near window object can be extinguished on time. At the same time, the temperature of the flue gas outside the window prevents the upper outer window glass to break and eventually suppressing the vertical spread of the fire and solving the problem and difficulties faced to save through the burning of the external wall effectively.

\section{Conclusion}

The high-rise building fire along the external wall of flammable materials and windows for vertical spreading combustion are undoubtedly on the weak link of fire 
protection engineering. It is also a confusion and difficulty faced by high-rise building fire protection. Therefore, it is very important to further strengthen the prevention, control and elimination of new and existing high-rise buildings through the analysis and demonstration of several cases of major fire outbreak in high-rise buildings throughout recent years. Besides, it is also a major fire safety issue faced by the construction and development of high-rise buildings. Adding an automatic fire-extinguishing water curtain system to the external wall of a high-rise building and a window automatic fire-extinguishing sprinkler on the top of the window is a simple and easy technical measure to solve this problem. As a conclusion, it is worth to promote and apply these safety measurements as soon as possible in the fire prevention measures of high-rise buildings.

\section{References}

[1] Sina.com, People.com, CCTV.com reported on CCTV New Building Annex Building, Shanghai Jingan District High-level Teacher Apartment and Shenyang Wanxin Building, texts, pictures and videos of several high-rise building fire accidents abroad.

[2] Fire Protection Code for High-rise Civil Building Design, GB50045-95, 2005 edition, Ministry of Public Security of the People's Republic of China, Ministry of Construction.

[3] Code for Design of Automatic Sprinkler System, GB500842015, 2015 edition, Ministry of Public Security of the People's Republic of China, Ministry of Construction. 